\title{
Organic acid, volatiles profile and sensory properties of ginger wines fermented by different yeasts
}

\author{
Dandan $\mathrm{Wu}^{1}$, Yuhong $\mathrm{Jin}^{1 *}$, Zhengtao Zhao ${ }^{2}$ \\ ${ }^{1}$ College of Food Science and Engineering, Shandong Agricultural University, Tai' an, Shandong Province, 271018, China; \\ ${ }^{2}$ College of Light Industry and Food Engineering, Guangxi University, Nanning, Guangxi Province, 530004, China;
}

\begin{abstract}
In this research, five yeasts were selected to ferment ginger juice to produce ginger wines. The changes of total sugar, reducing sugar, total acid, $\mathrm{pH}$ and alcohol content during fermentation were studied. The organic acid composition, aroma components and sensory properties of produced wine were analyzed. The results showed that all samples were fermented at a similar rate and the alcohol content reached $12 \%$, but the total acidity was significantly different. Wine $5 \#$ had the lowest concentration of succinic acid and highest concentrations of pyruvate acid and lactic acid. The flavor fingerprint of five kinds of ginger wines was developed by the Gas Chromatograph - Ion Mobility Spectrometer (GC-IMS). Among 82 identified compounds, around 32 volatiles were found to be unique compounds that related to the special yeast species used for the fermentation. PCA analysis results indicated that wine 4\# and 5\# had the highest similarity in volatile organic composition. However, they exhibited different sensory properties. Wine $5 \#$ had the highest preference score while wine $4 \#$ had the lowest preference among five wines. In general, Yeast 5\# provided the strongest and pleasant aroma, the best taste and sensory quality.
\end{abstract}

\section{Introduction}

Ginger is a flowering plant whose roots are widely used as spice or folk medicine. Ginger belongs to Zingiberaceae family ${ }^{[1]}$ and is rich in protein and dietary fiber. Due to its nutritional and functional properties, ginger roots are widely used in food industry. A variety of ginger products can be found in market, such as dried ginger, roasted ginger, pickled ginger, ginger powder and ginger tea.

Apart from its' nutritional properties, ginger has a special spicy taste, which can refresh brain and stimulate taste buds. Moreover, ginger is widely used in the pharmaceutical industry as a traditional and contemporary herbal medicine, which has antioxidant and anti-inflammatory efficacy ${ }^{[2]}$, neuroprotective and cognitive enhancing effects ${ }^{[3]}$, and prevents vomiting during pregnancy ${ }^{[4]}$. The composition of ginger roots has been reported to be rich in bioactive compounds such as gingerol, oxalic acid, diheptadiene, benzene, flavonoids, diterpenoids and sesquiterpenes. Among all those compounds, gingerol was found to be the major active ingredient in ginger roots ${ }^{[5]}$. Yogeshwer Shukla et al found that some of the Ginger's ingredients, such as phenolic beta-diphenolone, gingerol and diphenylheptane, were found to inhibit the production of lipid peroxide and scavenge free radicals after being absorbed by human body, which provided strong antioxidation and tumor inhibition effects ${ }^{[6]}$. Nowadays, ginger extracts have been widely used in antiinflammatory [7], anti-cancer [8], liver protection [9], antioxidant ${ }^{[10]}$, anti-hyperlipidemic effect ${ }^{[11]}$, and other aspects. Researches about the composition and the health benefits of ginger products have also gained great attention ${ }^{[12,13,14]}$.

Ginger has unique aroma. In a research by Ding et al [15], 55 volatile substances were identified in Laiwu ginger and the main components were found to be 1,3cyclohexadiene,5-(1,5-dimethyl-4-hexenyl)-2-methyl,

2,6-octadienal,3,7-dimethyl, cyclohexene,3-(1,5dimethyl-4-hexenyl)-6-methylene, $\beta$-phellandrene, $\alpha$ farnesene, camphene, and eucalyptol. In consideration of nutritional properties, health benefits and unique aroma of ginger, using ginger as material to develop functional food products is necessary. One possible product is the ginger fermented dry wine. However, seldom research conducted on the ginger wine can be found. One important factor that influences the quality and sensory properties of wines is the culture. Therefore, in order to produce ginger fermented wine with harmonious and pleasant aroma, it is essential to select suitable yeast.

The objective of this research is to investigate the effect of yeast variety on the fermentation properties, aroma profiles and sensory properties of ginger fermented wines. Five yeasts were selected in this research and the changes of organic acid, sugar and alcohol during fermentation were monitored. The volatiles and sensory properties of different wines were determined and compared. The results from this research could provide a theoretical basis for the scale production of ginger wine and the improvement of the quality of ginger wine.

\footnotetext{
* Corresponding author: yuhongjin79@sdau.edu.cn
} 


\section{Materials and methods}

\subsection{Materials}

Ginger roots were purchased from the local fruit market (Taian, China). Five yeasts were purchased from Lallemand Company (Toulouse, France), which were labeled as 1\#, 2\#, 3\#, 4\# and 5\# respectively. High temperature $\alpha$-amylase and saccharification enzyme were purchased from Novozymes Biotechnology Co., Ltd (Copenhagen, Denmark). Standards including oxalic acid, citric acid and succinic acid were purchased from Sigma Aldrich (St. Louis, MO, USA). Tartaric acid and $\alpha$-ketoglutaric acid were purchased from Fluka Company. L-malic acid, Tartaric acid and pyruvate acid were purchased from Aladdin (Shanghai, China). Lactic acid was ordered at Yuanye (Shanghai, China).

\subsection{Experimental methods}

\subsubsection{Process of ginger fermented wine.}

Fresh ginger roots were washed with tap water to remove impurities. After that, clean ginger roots were crushed into pulp by a Songtai brand st-400s crusher (Guangzhou, China) and pressed to produce ginger juice, which was mixed with sugar water $(1632 \mathrm{~g}$ sugar) to $8 \mathrm{~L}$ to achieve the concentration of gingerol up to $80 \mathrm{mg} / \mathrm{L}$. Active yeast was then added at a concentration of 0.6 $\mathrm{g} / \mathrm{L}$ and fermented at temperature $20-22^{\circ} \mathrm{C}$. The fermenting mash was stirred four times a day. The fermentation ending time was defined as when no change of the residual sugar in the must was detected over two consecutive days. The collected wine was then transferred and stored in a new jar at room temperature.

\subsubsection{Determination of quality indices of ginger fermented wine.}

Determination of the $\mathrm{pH}$, total acid, total sugar, alcohol, reducing sugar of the ginger fermented wine were according to the methods of GB/T 15038 -General Analytical Method for Wine and Fruit Wine of China.

\subsubsection{Determination of organic acids.}

The organic acids were determined by HPLC according to the Han's method ${ }^{[16]}$. Samples were injected after filtration through $0.22 \mu \mathrm{m}$ aqueous filter membrane. Nine standard organic acids were determined in this research, including oxalic acid, tartaric acid, pyruvate, malic acid, $\alpha$-ketoglutaric acid, lactic acid, acetic acid, citric acid and succinic acid. And regression equations of nine organic acids were according to Table 1 .

\subsubsection{Determination of volatile components.}

Volatile components of the example were determined by Gas Chromatograph - Ion Mobility Spectrometer (GCIMS) according to the methods of Guo ${ }^{[17]}$ and $\mathrm{Li}^{[18]}$ with slight modifications. A wax capillary column $(30 \mathrm{~m}$ $\times 0.32 \mathrm{~mm}$ ) was used for the separation. To release the volatiles in wine, Wine $(1 \mathrm{~mL})$ and distilled water $(4 \mathrm{~mL})$ was transferred to a $20 \mathrm{~mL}$ headspace bottle and incubated at $60^{\circ} \mathrm{C}$ for $20 \mathrm{~min} .500 \mu \mathrm{L}$ headspace was injected using a heated syringe $\left(50^{\circ} \mathrm{C}\right)$ into the heated injector $\left(80^{\circ} \mathrm{C}\right)$ in splitless mode. Nitrogen of $99.99 \%$ purity was used as a carrier gas at a programmed flow as follows: $2 \mathrm{~mL} / \mathrm{min}$ for $2 \mathrm{~min}$, raise the flow rate to 10 $\mathrm{mL} / \mathrm{min}$ in 48 minutes, $10 \mathrm{~mL} / \mathrm{min}$ for 200 milliseconds.

\subsubsection{Sensory evaluation.}

The aroma and typicality of the ginger fermented wines were sensorily evaluated and scored by 30 professional wine taster and they all had the professional qualification as a wine taster. And the evaluation standard was according to Table 2 .

Table 1. Regression equations of nine organic acids

\begin{tabular}{|c|c|c|c|}
\hline Organic acid & Regression equation & Correlation coefficient $\left(\mathrm{R}^{2}\right)$ & Linear range $(\mathrm{g} / \mathrm{L})$ \\
\hline Oxalic acid & $y=8693.84 x-95390.3$ & 0.9966 & $0.02-0.20$ \\
\hline Tartaric acid & $y=2296.71 x+61310.2$ & 0.9940 & $0.02-0.20$ \\
\hline Pyruvate & $y=10365.4 x-1600.80$ & 0.9986 & $0.05-0.50$ \\
\hline Malic acid & $y=1004.20 x+11785.3$ & 0.9988 & $0.05-0.50$ \\
\hline$\alpha$-ketoglutaric acid & $y=7910.05 x+14951.0$ & 0.9992 & $0.03-0.30$ \\
\hline Lactic acid & $y=721.033 x+964.581$ & 0.9984 & $0.10-1.00$ \\
\hline Acetic acid & $y=1455.04 x-5158.59$ & 0.9963 & $0.05-0.50$ \\
\hline Citric acid & $y=8257.42 x-36733.7$ & 0.9985 & $0.02-0.20$ \\
\hline Succinic acid & $y=553.147 x-20653.6$ & 0.9987 & $0.02-2.00$ \\
\hline
\end{tabular}


Table 2. Sensory evaluation standard of ginger fermented wine

\begin{tabular}{ll}
\hline & Evaluation standard \\
\hline Aroma & Fragrance: fresh ginger, fruity, apple, lemon, citrus, floral, wine; oxidized \\
$\left(40^{\prime}\right)$ & rotten apple flavor. \\
& Pleasant (10 points): pleasant aroma / fresh / fragrant. \\
& Richness (10 points): aroma rich and faint. \\
& Coordination (10 points): various aroma coordination / more coordinated / \\
& uncoordinated. \\
& Layering (10 points): The layering between different aromas is obvious/not \\
& obvious.
\end{tabular}

Taste $\quad$ Entrance (10 points): acidity, bitterness, irritating, ginger and spicy taste.

(40') Balance (10 points): Whether the taste is balanced.

Body (10 points): full/mellow/thick/light.

After taste (10 points): long / faint

Typical Whether it has the typical flavor of ginger fermented wine, unique flavor / (20') $\operatorname{good} / \mathrm{bad}$

\subsubsection{Statistical analysis.}

Statistical analysis was performed using SPSS Statistics 22. The instrumental analysis software of the aroma includes LAV (Laboratory Analytical Viewer) and three plug-ins as well as GC $\times$ IMS Library Search, which can be used for sample analysis from different angles. Differentiation analysis was carried out by DPS 7.05. Different letters indicated the significant differences between two points $(p<0.05)$. All data were the mean values of at least three parallel experiments.

\section{Results and discussion}

\subsection{Changes of $\mathrm{pH}$ and total acidity during fermentation}

The changes of $\mathrm{pH}$ and total acidity during fermentation process of ginger wine were exhibited in Fig. 1. As shown in Fig. 1A, the original $\mathrm{pH}$ of ginger mash was around 5.3. After inoculation with yeast, due to the slow fermentation of yeast at day 1 , the $\mathrm{pH}$ increased slightly at day 1 to $\mathrm{pH}$ value around 5.7. With the increase of the fermentation time, the $\mathrm{pH}$ values decreased rapidly. Ginger wines fermented by yeasts $2 \#$ and $5 \#$ exhibited slower decrease of $\mathrm{pH}$ from day 1 to day 3 compared to others. At day 4 , the $\mathrm{pH}$ of $2 \#$ and $5 \#$ fermented mash decreased, while the $\mathrm{pH}$ of the other three fermented mash increased slightly. All samples reached to a stable stage after day 9 and no further changes of $\mathrm{pH}$ were detected from day 9 to day 14, indicating the complete fermentation. Fig. 1B summarizes the changes of total acid during fermentation process. As expected, the total acid contents increased rapidly from day 1 to day 7 . No significant differences among different samples can be observed. In all cases, the total acid content reached to a plateau value after day 9, which was corresponding with the changes of $\mathrm{pH}$. The acidity of these five fermented wines decreased in the last 2-3 days of fermentation, which is related to the acid-reducing ability of yeast, indicating that these five kinds of yeast had acid reducing ability ${ }^{[19]}$. Among them, 4\# yeast had the fastest acid reduction rate. Sample containing yeast 1\# had the highest total acid content $(3.11 \mathrm{~g} / \mathrm{L})$ while wine $4 \#$ had the lowest total acid content $(2.51 \mathrm{~g} / \mathrm{L})$.
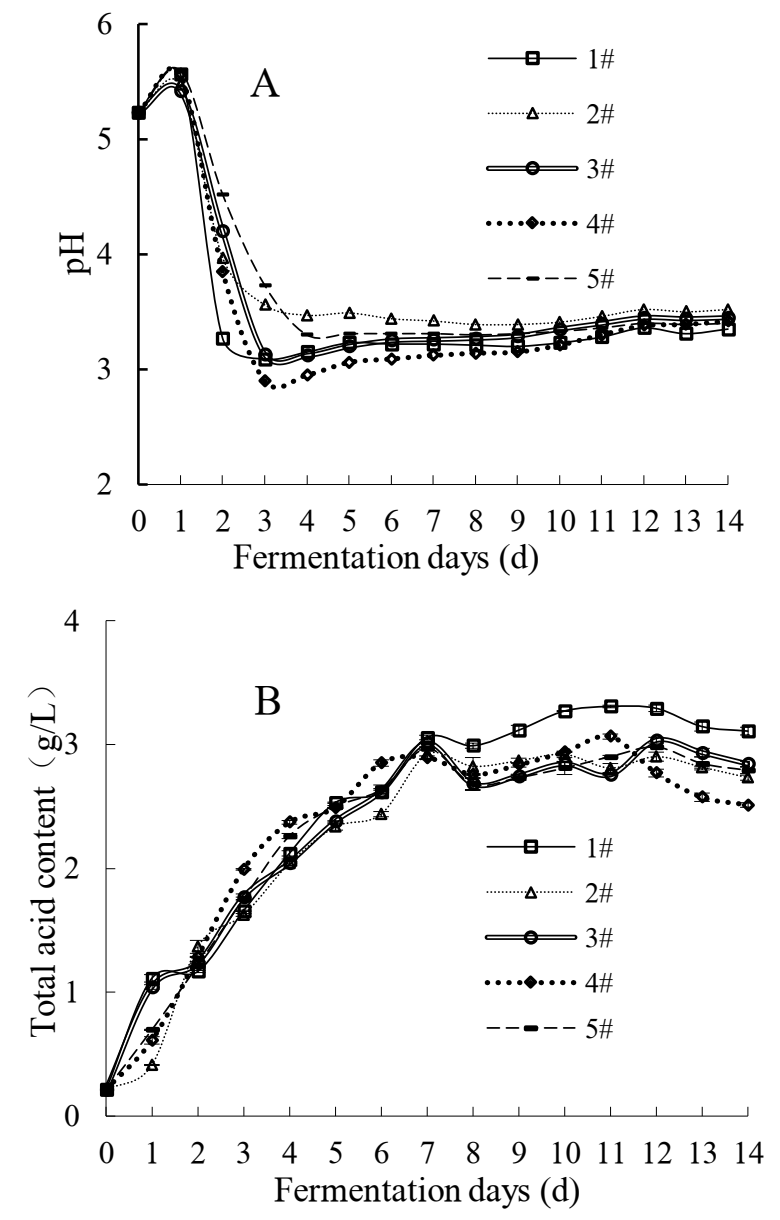

Fig. 1. Changes of $\mathrm{pH}$ and total acidity during fermentation of ginger wine

A. pH. B. Total acidity 


\subsection{Changes of total sugar, alcohol and reducing sugar during fermentation}

Fig. 2 summarizes the changes of total sugar (A), alcohol (B) and reducing sugar (C) during the fermentation process. Fig. 2A showed that total sugar content decreased rapidly during the fermentation period. Total sugar content of sample $2 \#$ reduced faster compared to other sample, demonstrating the fastest fermentation rate of $2 \#$ yeast. During fermentation process, the total alcohol content (Fig. 2B) increased rapidly from day 1 to day 10. Sample 2\# showed the highest alcohol content, which was in agreement with the changes of total sugar content. However, after day 10, all samples reached to a plateau and stabilized at a same alcohol level, indicating the complete fermentation.

To better characterize the fermentation process, the changes of reducing sugar content was also monitored and the results were shown in Fig. 2C. The content of reducing sugar increased sharply from day 0 to day 2 , which was due to the yeast which converted sucrose to reducing sugar. The sucrose conversion rates of the five yeasts were quite different as shown in Table 3. At day 1, about $78.3 \%$ of sucrose was converted by yeast $3 \#$, which was the highest among all samples. The $2 \#$ yeast converted $57.14 \%$ of sucrose to reducing sugar at day 1 , followed by $5 \#, 4 \#$ and $1 \#$ yeasts, which had conversion rates of $46.85 \%, 40.86 \%$ and $37.74 \%$ respectively. At day 2 , more than $80 \%$ of sucrose was converted by all five samples. Further increase of the fermentation time, the reducing sugar content decreased rapidly. This is due to the transfer of reducing sugar to alcohol due to the fermentation. The reducing sugar content reached to the lowest value at about day 9 and no further decrease was detected. Sample 2\# exhibited the fastest reduction (Fig. $2 \mathrm{~A}$ ), which was in agreement with the changes of alcohol content (Fig. 2B).
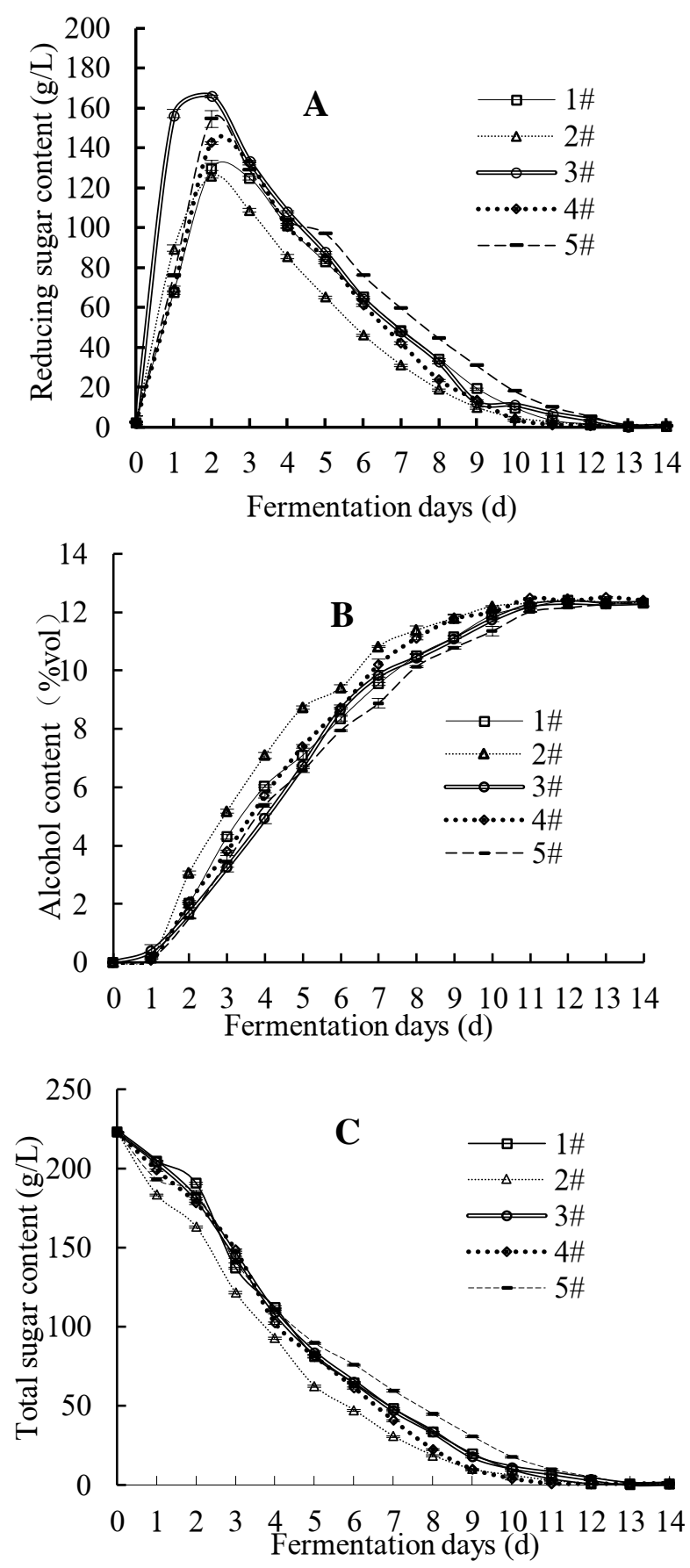

Fig. 2. Change of fermented mash during fermentation of ginger fermented wine

A. Total sugar. B. Alcohol. C. Reducing sugar.

Table 3. Sucrose conversion rate of five yeasts (\%)

\begin{tabular}{cccccc}
\hline & $1 \#$ & $2 \#$ & $3 \#$ & $4 \#$ & $5 \#$ \\
\hline D-1 & 37.74 & 57.14 & 78.3 & 40.86 & 46.85 \\
D-2 & 34.56 & 25.92 & 14.9 & 43.07 & 39.64 \\
D-3 & 22.03 & 11.13 & 1.45 & 8.72 & 7.96 \\
D-4 & 0.56 & 2.39 & 5.05 & 6.56 & 2.18 \\
D-5 & 5.11 & 3.42 & 0.3 & 0.79 & 3.37 \\
\hline
\end{tabular}




\subsection{Quality-indices of five ginger wines}

Table 4 shows the indicators of the finished wine. Wine produced by yeast $4 \#$ had minimum fermentation days of 11 days and wine $3 \#$ and $5 \#$ had the longest fermentation period of 13 days. The total sugar and reducing sugar contents in five finished wines were all reduced to below $4 \mathrm{~g} / \mathrm{L}$ and the alcohol content all reached to a similar value of $12.31-12.40 \%$ vol $(\mathrm{P}>0.05)$. However, slight differences in the total acid content of the ginger wines were observed $(\mathrm{P}<0.05)$. The acidity of ginger fermented wine fermented by yeast $1 \#$ had the highest total acid of $3.11 \mathrm{~g} / \mathrm{L}$ while yeast $4 \#$ had the lowest value of $2.51 \mathrm{~g} / \mathrm{L}$.

\subsection{Organic acid content of five ginger wines}

The composition and content of organic acids play an important role in the overall flavor of wine. Table 5 summarizes the concentrations of 9 acids in the wines. In general, wine $2 \#$ had the highest total acid content of $2816.42 \pm 9.48 \mathrm{mg} / \mathrm{L}$, followed by wine $1 \#$ with a value of $2557.13 \mathrm{mg} / \mathrm{L}$. Significant differences among the five samples were found $(\mathrm{P}<0.05)$. Previous report verified that strain variability among Saccharomyces cerevisiae causes differences in organic acid content ${ }^{[20]}$. The contents of 9 organic acids in 5 ginger wines were significantly different. And the content of succinic acid was the highest in the five

Table 4. Quality-indices of five ginger wines

\begin{tabular}{cccccc}
\hline & $1 \#$ & $2 \#$ & $3 \#$ & $4 \#$ & $5 \#$ \\
\hline Fermentation Days (d) & 12 & 12 & 13 & 11 & 13 \\
Total Sugar (g/L) & $0.83 \pm 0.13 \mathrm{a}$ & $0.66 \pm 0.29 \mathrm{a}$ & $0.79 \pm 0.21 \mathrm{a}$ & $1.2 \pm 0.13 \mathrm{a}$ & $1.16 \pm 0.21 \mathrm{a}$ \\
Reducing Sugar (g/L) & $0.66 \pm 0.03 \mathrm{a}$ & $0.71 \pm 0.02 \mathrm{a}$ & $0.73 \pm 0.06 \mathrm{a}$ & $0.76 \pm 0.03 \mathrm{a}$ & $0.69 \pm 0.03 \mathrm{a}$ \\
Alcohol (\%vol) & $12.31 \pm 0.02 \mathrm{a}$ & $12.33 \pm 0.02 \mathrm{a}$ & $12.32 \pm 0.01 \mathrm{a}$ & $12.40 \pm 0.04 \mathrm{a}$ & $12.33 \pm 0.01 \mathrm{a}$ \\
Total Acidity (g/L) & $3.11 \pm 0.02 \mathrm{a}$ & $2.95 \pm 0.01 \mathrm{~b}$ & $2.84 \pm 0.01 \mathrm{~b}$ & $2.51 \pm 0.01 \mathrm{~d}$ & $2.79 \pm 0.02 \mathrm{c}$ \\
$\mathrm{pH}$ & $3.35 \mathrm{e}$ & $3.52 \mathrm{a}$ & $3.45 \mathrm{~b}$ & $3.42 \mathrm{c}$ & $3.40 \mathrm{~d}$ \\
\hline
\end{tabular}

Data are expressed as mean \pm standard deviation. The same alphabets in right side of the same line show no significance $(\mathrm{P}>0.05)$, on the contrary, having significance $(\mathrm{P}<0.05)$.

Table 5. Organic acid analysis results of ginger fermented wine $(\mathrm{mg} / \mathrm{L})$

\begin{tabular}{cccccc}
\hline Organic Acid & $1 \#$ & $2 \#$ & $3 \#$ & $4 \#$ & $5 \#$ \\
\hline Oxalic acid & $24.42 \pm 0.07 \mathrm{c}$ & $43.70 \pm 1.33 \mathrm{~b}$ & $49.90 \pm 0.41 \mathrm{ab}$ & $61.38 \pm 0.35 \mathrm{a}$ & $65.40 \pm 12.03 \mathrm{a}$ \\
Pyruvate acid & $100.69 \pm 0.04 \mathrm{~d}$ & $95.58 \pm 1.01 \mathrm{e}$ & $140.67 \pm 0.17 \mathrm{~b}$ & $127.84 \pm 1.54 \mathrm{c}$ & $172.68 \pm 0.41 \mathrm{a}$ \\
L-malic acid & $365.88 \pm 11.18 \mathrm{~b}$ & $457.27 \pm 0.50 \mathrm{a}$ & $98.89 \pm 3.41 \mathrm{e}$ & $321.37 \pm 5.43 \mathrm{c}$ & $148.81 \pm 1.68 \mathrm{~d}$ \\
$\alpha$-ketoglutaric acid & $47.10 \pm 0.62 \mathrm{~d}$ & $76.43 \pm 0.23 \mathrm{~b}$ & $46.27 \pm 1.28 \mathrm{~d}$ & $88.70 \pm 0.51 \mathrm{a}$ & $60.58 \pm 1.18 \mathrm{c}$ \\
Lactic acid & $299.80 \pm 2.46 \mathrm{c}$ & $310.24 \pm 6.72 \mathrm{c}$ & $361.64 \pm 11.03 \mathrm{~b}$ & $351.21 \pm 1.56 \mathrm{~b}$ & $434.50 \pm 9.65 \mathrm{a}$ \\
Acetic acid & $417.72 \pm 4.62 \mathrm{~d}$ & $464.78 \pm 4.95 \mathrm{c}$ & $558.20 \pm 17.33 \mathrm{~b}$ & $412.21 \pm 8.08 \mathrm{~d}$ & $521.44 \pm 18.87 \mathrm{a}$ \\
Citric acid & $65.32 \pm 0.28 \mathrm{~b}$ & $87.35 \pm 0.36 \mathrm{a}$ & $30.08 \pm 1.68 \mathrm{c}$ & $86.52 \pm 2.47 \mathrm{a}$ & $33.45 \pm 2.05 \mathrm{c}$ \\
Succinic acid & $1336.30 \pm 8.08 \mathrm{~b}$ & $1424.14 \pm 2.51 \mathrm{a}$ & $918.71 \pm 39.80 \mathrm{c}$ & $1017.86 \pm 8.17 \mathrm{~d}$ & $860.01 \pm 14.46 \mathrm{e}$ \\
Total organic acid & $2657.22 \pm 14.89 \mathrm{~b}$ & $2939.49 \pm 11.24 \mathrm{a}$ & $2204.36 \pm 53.11 \mathrm{e}$ & $2467.04 \pm 1.64 \mathrm{c}$ & $2296.87 \pm 26.69 \mathrm{~d}$ \\
\hline
\end{tabular}

Data are expressed as mean \pm standard deviation. The same alphabets in right side of the same line show no significance $(\mathrm{P}>0.05)$, on the contrary, having significance $(\mathrm{P}<0.05)$.

wines, succinic acid was mainly derived from the metabolic process of Saccharomyces cerevisiae and provided sourness, astringency and bitterness to the wine products. Acetic acid was the second highest organic acid. Wine $3 \#$ had the highest acetic acid content of $566.29 \mathrm{mg} / \mathrm{L}$, followed by wine $5 \#$. Wine $2 \#$ had the lowest content of pyruvic acid value of $95.81 \mathrm{mg} / \mathrm{L}$ while it had the highest concentrations of succinic acid, citric acid and L-malic acid compared with other samples. Moreover, the contents of pyruvic acid, lactic acid and $\alpha$-ketoglutaric acid were also different among samples. Wine 5\# had the highest pyruvic acid and lactic acid while wine $4 \#$ had the highest $\alpha$-ketoglutaric acid. Apparently, the organic acid compositions in wines produced from different yeast are quite different, which will further influence the aroma and sensory properties of ginger wines.

\subsection{Aroma comparison of five ginger wines}

Fingerprints of organic volatile compounds in five ginger wines are shown in Fig. 3. As shown, a total number of 82 organic volatile compounds were detected. Twenty-nine organic volatile compounds were identified in the database by GC-IMS, including 9 kinds of ketones, 6 kinds of aldehydes, 6 kinds of esters, 5 kinds of alcohols, 1,8-eucalyptol and benzene and styrene.

Based on the analysis, the detected volatile organic compounds can be classified into three categories.

The first category includes the volatile compounds that were not changed substantially due to different yeast species, which were labeled in the region $\mathrm{H}$ in Fig 3, including ethyl acetate, pentanol, 1-butanol and styrene, 
which were solely originated from ginger juice instead of the fermentation process.

The second category includes the volatile compounds that presented in all five ginger wines and which concentrations were significantly influenced by the type of the yeast, such as the substance indicated in region I, including 20 compounds such as acrolein, propanol and propionaldehyde.

The third category is the organic volatile compounds that were unique to each ginger wine. The volatiles contained in this category are closely related to the yeast species and can provide unique flavor for wine fermented by different yeast. They are derived from the yeast itself and the hydrolysis of the aroma precursors during yeast fermentation process. The special volatiles for wine $1 \#$ were indicated in the region $\mathrm{J}$, which contained 12 organic compounds such as butyraldehyde, which was the main unique compound for this wine. On the other hand, there were 7 unique volatiles for the wine
2\#, such as propyl acetate, as indicated by the region $\mathrm{K}$. Three special volatiles were detected for wines both $3 \#$ and $4 \#$, which were shown in the region $\mathrm{L}$ and $\mathrm{M}$, respectively. Wines $4 \#$ and $5 \#$ shared 7 volatile compounds such as propionaldehyde, as indicated in the region $\mathrm{N}$, which were significantly higher than other three ginger wines. The unique volatiles for each wine were the main factors that can be used to distinguish one wine from others.

Fig. 4 showed PCA analysis results for the signal intensities of all volatile organic compounds as summarized in fig. 3. Different colors in the figure represent ginger wines produced from different yeast, A and B represent two parallels. As can be seen, wines $4 \#$ and $5 \#$ both closely positioned, indicating they had the highest similarity in volatile organic composition. On the other hand, wines $1 \#, 2 \#$ and $3 \#$ were separated from each other, which implied low similarity in volatile organic composition among them.
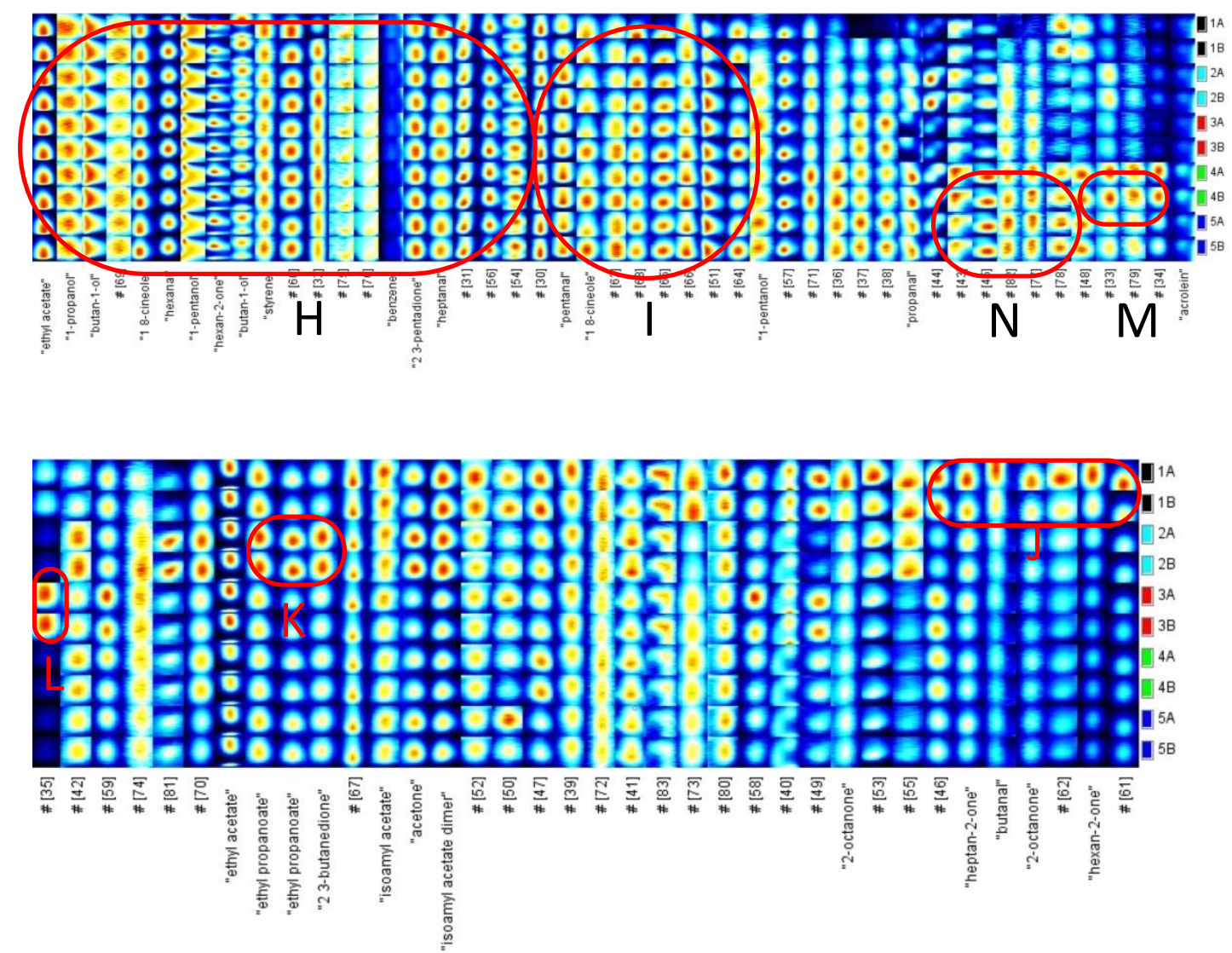

Fig. 3. Fingerprint of organic volatile compounds in different yeast fermented ginger wine. (On the right side of the figure, the number 1, 2, 3, 4, 5 represent the sample, and A \& B represent two parallels. In the figure, H, I, J, K, L, M and N represent aroma regions from different sources.) 


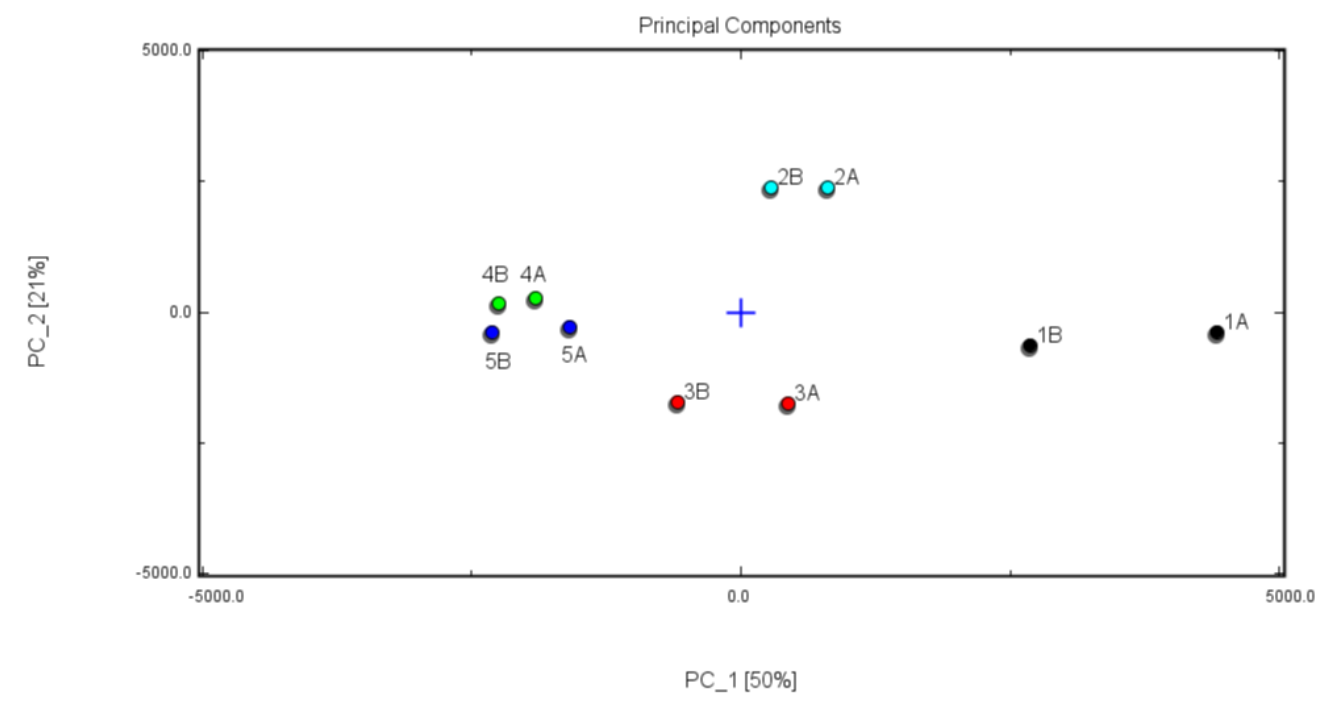

Fig. 4. PCA analysis results of volatiles in different ginger wines.
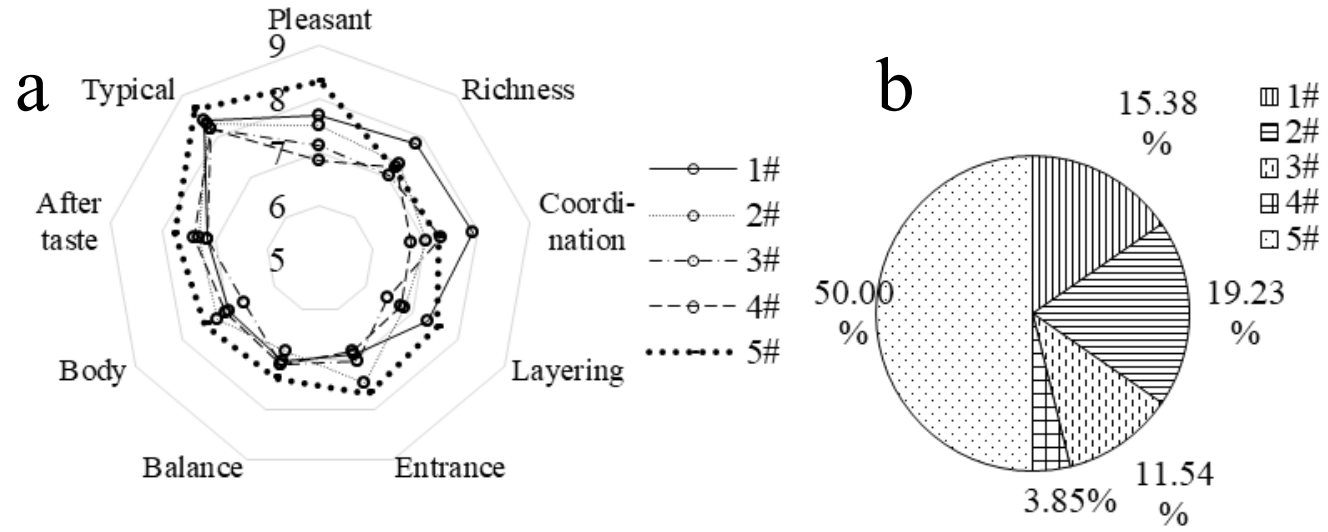

Fig. 5. Sensory evaluation (a) score and affection (b) of five ginger wines

\subsection{Sensory evaluation of five ginger wines}

Fig. 5a summarizes the sensory evaluation results for five ginger wines. The ginger wine $1 \#$ was rich in fruit aroma and had the best coordination among aromas. The ginger wine $2 \#$ had the most mellow body. Although wines $4 \#$ and $5 \#$ showed great similarity from the analysis results of volatiles (Fig. 4), the two wines exhibited significant different sensory properties. Compared to wine 4\#, wine 5\# had better pleasant aroma, more obvious fruit aroma and better aftertaste. From the affection results (Fig. 5b), ginger wine $5 \#$ had the highest preference score of $50 \%$, followed by wine $2 \#$ of $19.23 \%$ and wine $1 \#$ of $15.38 \%$. Wine $4 \#$ had the lowest preference value of $3.85 \%$.

\section{Conclusion}

The organic acid composition, aroma components and sensory properties of five ginger wine fermented by different yeast were analyzed. The five ginger wines had similar alcohol, total and reducing sugar contents but had significant different concentration of total acidity and wine $2 \#$ had the highest amount of total organic acid content. The contents of 9 organic acids in 5 ginger wines were significantly different, and succinic acid was the highest acid in all wines. Among 82 identified compounds, around 32 volatiles were found to be unique compounds that related to the special yeast species used for the fermentation. PCA analysis results indicated that wine $4 \#$ and $5 \#$ had the highest similarity in volatile organic composition. However, wine 5\# showed the highest preference while wine $4 \#$ had lowest preference score. 


\section{Acknowledgements}

This study was supported by the key research and development program of Shandong Province (2017GNC10105 Title: The key technology of ginger wine industrialization and the comprehensive utilization of the by-products).

\section{References}

1. W. Si, Y.P. Chen, J. Zhang, Z.Y. Chen, H.Y. Chung, Food Chem 239, 1117-1125 (2017)

2. J. Abdollah, A.P. Reyhane, N. Maryam, T. Zahra, S. Ali, A. Fatemeh, M.H. Zuhair, Drug Res. 67(11), 632-639 (2017)

3. C. Sutalangka, J. Wattanathorn, BMC Complement Altern. Med. 17, 135-146. (2017)

4. D. Pongrojpaw, Am. J. Obstet. Gynecol. 90, 17031709 (2006)

5. Y. Sivasothy, W.K. Chong, A. Hamid, I.M. Eldeen, S.F. Sulaiman, K. Awang, J. Food Chem. 124, 514517 (2011)

6. Y. Shukla, M. Singh, J. Food Chem. Tox. 45, 683690 (2007)

7. N. Aryaeian, H. Tavakkoli, J. Adv. Food Technol Nutr Sci Open. 1, 97-101 (2015)

8. S. Prasad, A.K. Tyagi, Gastroenterol. Res. Pract. 11, 1-11 (2015)

9. C.S. Ezeonu, P.A.C. Egbuna, L.U.S. Ezeanyika, C.G. Nkwonta, N.D. Idoko, Res. J. Med. Sci. 5, 102-107 (2011)

10. S. Wang, C. Zhang, G. Yang, Y. Y Nat. Prod. Commun. 9, 1027-1030 (2014)

11. M. Thomson, K.K. Al-Qattan, S.M. Al-Sawan, M.A. Alnaqeeb, I. Khan, M. Ali, Prostagl Leukotr Essen. Fat Acids. 67, 475-478 (2002)

12. M. Sharifi-Rad, E.M. Varoni, B. Salehi, J. SharifiRad, K.R. Matthews, S.A. Ayatollahi, F. Kobarfard, S.A. Ibrahim, D. Mnayer, Z.A. Zakaria, M. SharifiRad, Z. Yousaf, M. Iriti, A. Basile, D. Rigano, J. Molecules, 22, 2145 (2017)

13. J. Wang, W. Ke, R. Bao, X. Hu, F. Chen, Ann N Y Acad Sci. 1398, 83-98 (2017)

14. V. Ebrahimzadeh Attari, A. Malek Mahdavi, Z. Javadivala, S. Mahluji, S. Zununi Vahed, A. Ostadrahimi, Phytother Res. 32, 577-585 (2017)

15. H. Ding, K.J. An, C.P. Zhao, Y. Li, Y.H. Guo, Z.F. Wang, Food Bioprod Process. 90, 515-524 (2012)

16. Y.Y. Han, J.H. Du, J. Li, M.M. Li, Molecules (Basel, Switzerland), 24, 2510 (2019)

17. Y. Guo, D. Chen, Y,F. Dong, H.P. Ju, C. Wu, S.Y. Lin, J. Chromatogr. B. 1099, 46-55 (2018)

18. M.Q. Li, R.W. Yang, H. Zhang, S.L. Wang, D. Chen, S.Y. Lin, Food Chem. 290, 32-39 (2019)

19. J.T. Hu, Shandong Agricultural University, (2012)
20. S. Wang, Y. Li, J. Ren, P. Gu, T. Li, Y. Wu, B. Xhang, B. Zhu, Food Biosci. 22, 121-128 (2018) 